\title{
Use of Buckwheat Straw to Produce Ethyl Alcohol Using Ionic Liquids
}

\author{
Małgorzata Smuga-Kogut ${ }^{1}$, Leszek Bychto ${ }^{2}{ }^{-}$, Bartosz Walendzik ${ }^{3}$, Judyta Cielecka-Piontek ${ }^{4}$, \\ Roman Marecik ${ }^{5}$, Joanna Kobus-Cisowska ${ }^{6}{ }^{\mathbb{D}}$, Katarzyna Grajek ${ }^{7}$ and \\ Daria Szymanowska-Powałowska ${ }^{5, *}$ \\ 1 Department of Agrobiotechnology, Faculty of Mechanical Engineering, Koszalin University of Technology, \\ Raclawicka 15-17, 75-620 Koszalin, Poland; malgorzta.smuga.kogut@tu.koszalin.pl \\ 2 Department of Electronics, Faculty of Electronics and Computer Science, Koszalin University of Technology, \\ Sniadeckich 2, 75-453 Koszalin, Poland; leszek.bychto@tu.koszalin.pl \\ 3 Department of Civil Engineering, Environmental and Geodetic Sciences, Koszalin University of Technology \\ Koszalin, Sniadeckich 2, 75-453 Koszalin, Poland; bartosz.walendzik@tu.koszalin.pl \\ 4 Department of Pharmacognosy, Poznan University of Medical Sciences, Swiecickiego 4, 60-781 Poznan, \\ Poland; jpiontek@edu.ump.pl \\ 5 Department of Biotechnology and Food Microbiology, Poznan University of Life Sciences, \\ Wojska Polskiego 48, 60-627 Poznan, Poland; roman.marecik@up.poznan.pl \\ 6 Department of Gastronomical Sciences and Functional Foods, Poznan University of Life Sciences, \\ Wojska Polskiego, 60-637 Poznan, Poland; joanna.kobus-cisowska@up.poznan.pl \\ 7 Institute of Natural Fibers and Medical Plants, Wojska Polskiego 71b, 60-630 Poznan, Poland; \\ katarzyna.grajek@iwnirz.pl \\ * Correspondence: daria.szymanowska@up.poznan.pl
}

Received: 8 March 2019; Accepted: 10 May 2019; Published: 26 May 2019

\begin{abstract}
Background: Common buckwheat (Fagopyrum esculentum Moench) is an annual spring-emerging crop that is classified among the dicotyledons, due to the manner of its cultivation, use, and chemical composition of seeds. The use of buckwheat straw for energy purposes-for example, for the production of second generation bioethanol-might enable its wider application and increase the cost-effectiveness of tillage. Methods: In this study, we examined the usability of buckwheat straw for the production of bioethanol. We pretreated the raw material with ionic liquids and subsequently performed enzymatic hydrolysis and alcoholic fermentation. The obtained chemometric data were analyzed using the Partial Least Squares (PLS) regression model. PLS regression in combination with spectral analysis within the near-infrared (NIR) spectrum allowed for the rapid determination of the amount of cellulose in the raw material and also provided information on the changes taking place in its structure. Results: We obtained good results for the combination of 1-ethyl-3-methylimidazolium acetate as the ionic liquid and Cellic CTec2 as the enzymatic preparation for the pretreatment of buckwheat straw. The highest concentration of glucose following $72 \mathrm{~h}$ of enzymatic hydrolysis was found to be around $5.5 \mathrm{~g} / \mathrm{dm}^{3}$. The highest concentration of ethanol $\left(3.31 \mathrm{~g} / \mathrm{dm}^{3}\right)$ was obtained with the combination of 1-butyl-3-methylimidazolium acetate for the pretreatment and cellulase from Trichoderma reesei for enzymatic hydrolysis. Conclusions: In summary, the efficiency of the fermentation process is strictly associated with the pool of available fermenting sugars, and it depends on the type of ionic liquid used during the pretreatment and on the enzymatic preparation. It is possible to obtain bioethanol from buckwheat straw using ionic liquid for pretreatment of the raw material prior to the enzymatic hydrolysis and alcoholic fermentation of the material.
\end{abstract}

Keywords: bioethanol; biomass; buckwheat straw; ionic liquid; pretreatment 


\section{Introduction}

Common buckwheat (Fagopyrum esculentum Moench) is an annual spring-emerging crop that is classified among the dicotyledons; yet, due to the manner of its cultivation and use, and the chemical composition of its seeds, it is classified as a pseudocereal. The buckwheat stem grows up to a height of $60-100 \mathrm{~cm}$ and bears branches; it contains pigments such as anthocyanins [1]. The advantage of buckwheat cultivation is that it is a low-soil forecrop whose demands are associated with its capacity to absorb components that are poorly available to other plants and thus better uses soil fertility. Poland is a large producer of buckwheat (118,562 $\mathrm{t}$ ), and according to FAO data (FAO Reports, 06.09.2018), it ranks fifth in terms of global buckwheat production. Russia $(1,186,333 \mathrm{t})$ occupies the first place, followed by China (404,259 t), Ukraine (176,430 t), and France $(122,206 \mathrm{t})$. The use of buckwheat straw for energy purposes-for example, for the production of second generation bioethanol-might enable its wider application and increase the cost-effectiveness of tillage. Pretreatment of biomass is a crucial step in this conversion. In this context ionic liquid pretreatment of biomass has received much attention lately. The work presented her investigates the effect of pretreatment of chosen lignocellulosic materials with ionic liquids to increase the enzymatic degradation into monosaccharides and to the alkoholic fermentation. However, since the physico-chemical characteristics vary considerably between the different lignocellulosic materials, it is necessary to adopt suitable pretreatment technologies based on the properties of each raw material [2].

One of the methods of pretreatment of compound raw materials of the lignocellulosic complex is the treatment of raw material with ionic liquids [3]. Ionic liquids are organic solvents with a melting point below $100^{\circ} \mathrm{C}$; they consist of large organic cations and minor inorganic anions $[4,5]$. Advantages of these "green solvents" include the possibility to select from a large range of cations and anions, which enables the design of liquids for specific use [3]. Some of the properties of ionic liquids can be tuned to deliver a specific purpose such as melting point, thermal stability, refractive index, acid-base character, hydrophilicity, polarity, density, and viscosity [4]. The capacity of ionic liquids to dissolve cellulosic and lignocellulosic biomass is a commonly studied topic in the search for new production methods for liquid biofuels. However, the mechanism of action of ionic liquids is not fully understood. An important aspect in the purification of lignocellulose with ionic liquids is the reduction of the crystallization of cellulose after the use of treatments that influences the use of the highest possible concentration of fermenting sugars; that is, after enzymatic hydrolysis [6]. Pretreatment of biomass is a crucial step in this conversion of sugar to alcohol. In this context, pretreatment of biomass using ionic liquids has recently received much attention [7]. Therefore, in this study, we aimed to investigate the effect of pretreatment of selected lignocellulosic materials with ionic liquids in order to increase the enzymatic degradation and produce monosaccharides and thereby to increase the alcoholic fermentation. However, since physicochemical characteristics vary considerably between the different lignocellulosic materials, it is necessary to adopt suitable technologies of pretreatment based on the properties of each raw material [2]. In order to be able to use ionic liquids in the future for biomass processing on an industrial scale, several aspects related to the recycling of ionic liquid after dissolving cellulose (lignin purification and ionic liquid dehydration) as well as thermal stability of the ionic liquid mixture with biomass should be clarified. Some scientific studies indicate that imidazolic ionic liquids lose their thermal stability at temperatures above $100{ }^{\circ} \mathrm{C}$ [3]. Therefore, in this study, we aimed to assess the possibility of using buckwheat straw for the production of ethyl alcohol with the use of various ionic liquids for the pretreatment of the biomass. The task of ionic liquids is to change the structure of cellulose fibers from crystalline to amorphous, increasing the space between the fibers and removal of lignin - the inhibitor of the subsequent hydrolysis and fermentation processes. To this end, 4 different ionic liquids were used for buckwheat pretreatment. Moreover, a variant where buckwheat straw was treated with 2 ionic liquids was verified (in a cascade system). The objective of this treatment was the removal of lignin with the use of EMIM Cl and change of the cellulose structure and disrupt the bonds between fibers via EMIM OAc. 


\section{Materials and Methods}

\subsection{Raw Material}

Buckwheat straw (stems of common buckwheat) were collected in September 2018 from a field with a surface area of 12 ha (Kosciernica, Poland). The material was dried in a convection dryer at a temperature of $85^{\circ} \mathrm{C}$ to reach a water content of $5 \%$, and subsequently ground in a colloidal mill (Probs \& Class, Rastatt, Germany). The contents of dry weight, cellulose, lignin, and hemicellulose were determined in the straw. The ground material was subjected to enzymatic hydrolysis and fermentation, both without prior pretreatment and with the use of material purification with four ionic liquids in order to select the correct solvent to increase the proportion of cellulose and hemicellulose fibers available to cellulolytic enzymes.

\subsection{Ionic Liquids}

Four types of ionic liquids were used in the pretreatment of the raw material: 1-ethyl-3-methylimidazolium acetate (EMIMOAc), 1-butyl-3-methylimidazolium acetate (BMIMOAc), 1-ethyl-3-methylimidazolium diethyl phosphate (EMIMDEP), and 1-ethyl-3-methylimidazolium chloride (EMIMCl). One of the samples was subjected to two-fold purification with the use of EMIMOAc and then with EMIMCl. Briefly, $5 \mathrm{~g}$ of buckwheat straw was dissolved in $50 \mathrm{~cm}^{3}$ of the given ionic liquid and then heated to $120^{\circ} \mathrm{C}$ for $2 \mathrm{~h}$. Then, the material was brought to room temperature (allowed to cool to room temperature) and then deionized water was added, which resulted in the precipitation of lignocellulose. The material was washed several times with deionized water and then dried at $105^{\circ} \mathrm{C}$ for $1.5 \mathrm{~h}$. In the case of using a double treatment with ionic liquids (EMIMOAc and EMIMCl), first $5 \mathrm{~g}$ of biomass was dissolved in $50 \mathrm{~cm}^{3} \mathrm{EMIMCl}\left(120^{\circ} \mathrm{C}, 2 \mathrm{~h}\right)$, subsequently the ionic liquid was rinsed with water, and the material was dried at $105^{\circ} \mathrm{C}$ for $1.5 \mathrm{~h}$. The dried material was treated once again using EMIMOAc $\left(120^{\circ} \mathrm{C}, 2 \mathrm{~h}\right)$ and biomass was precipitated from IL and dried at temperature $105^{\circ} \mathrm{C}$ for $1.5 \mathrm{~h}$.

\subsection{Enzymatic Hydrolysis}

In the process of enzymatic hydrolysis, three cellulolytic agents were used: cellulase from Aspergillus species ( $\geq 1000$ units/g; aqueous solution, Merck, Germany), cellulase from Trichoderma reesei ( $\geq 700$ units/g, aqueous solution; Merck, Germany), and Cellic CTec2 (223 FPU/mL; aqueous solution, Merck, Germany). The conditions of hydrolysis were adjusted to the requirements specified in the manufacturer's guidelines; in the case of cellulase from T. reesei $\left(20 \mathrm{U} \cdot \mathrm{g}^{-1} \mathrm{~d} \cdot \mathrm{m}\right.$. biomass $)$ and from Aspergillus species $\left(20 \mathrm{U} \cdot \mathrm{g}^{-1} \mathrm{~d} . \mathrm{m}\right.$. biomass), the temperature of hydrolysis was equal to $47^{\circ} \mathrm{C}$ at $\mathrm{pH}$ 4.8. In the case of the Cellic CTec2 (25 FPU g ${ }^{-1} \mathrm{~d}$.m. biomass) agent, the temperature of hydrolysis was equal to $50{ }^{\circ} \mathrm{C}$ at $\mathrm{pH}$ 5.0. In the process of hydrolysis, $0.5 \mathrm{~g}$ of buckwheat straw $(98.7 \%$ dry weight) was dissolved in $50 \mathrm{~cm}^{3}$ of acetate buffer $(50 \mathrm{mM})$ and saccharified for $96 \mathrm{~h}$ under continuous stirring in a shaker at $150 \mathrm{rpm}$. After this, the samples were decanted, and the solution was used for alcoholic fermentation.

\subsection{Alcoholic Fermentation}

Hydrolysate solutions previously filtered to separate the lignocellulose residue were subjected to alcoholic fermentation. The $\mathrm{pH}$ of the fermentation broth was measured at each sampling and adjusted to 5.0 by addition of either $10 \mathrm{wt} . \% \mathrm{H}_{2} \mathrm{SO}_{4}$ or $20 \mathrm{wt} . \% \mathrm{NaOH}$. Solutions after enzymatic hydrolysis $\left(40 \mathrm{~cm}^{3}\right)$ were separated from the solid fraction of lignocellulose and transferred to $50 \mathrm{~cm}^{3}$ fermentation flasks sealed with a fermentation bung, and filled with distilled water. Fermentation was started by the addition of freeze-dried distiller's yeast: Saccharomyces cerevisiae type II (Sigma-Aldrich, Germany) $(5 \% \mathrm{w} / \mathrm{v})$. Ethanol fermentation was conducted for 4 days, at a temperature of $36{ }^{\circ} \mathrm{C}$, with shaking at $100 \mathrm{rpm}$. Samples were taken and analyzed for ethanol concentrations after fermentation. The yeast 
cell population and viability were determined by a direct microscopic count in a counting chamber after staining with methylene blue.

\subsection{Analytical Methods}

In order to examine the influence of ionic liquids on the structure of lignocellulose and on the amount of available cellulose, all samples were tested for their content of cellulose, lignin, and hemicellulose (Ankom A200; ANKOM Technology); the crystalline structure of the samples was recorded using a scanning electron microscope (SEM), electron microscope and NIR spectrum. The morphology of cellulose fibers in buckwheat straw samples prior to and after ionic liquid pretreatment was recorded using an SEM FEI Quanta 200 Mark 2. Multidimensional analysis of primary components, i.e., the principal component analysis (PCA), was used to indicate the significance of the influence of individual factors in the given variant on the content of free cellulose fibers and the effects of interactions between individual factors. The measurement of NIR was performed using a DLP NIRscan Nano spectrophotometer (Texas Instruments), using the reflection technique (in order to obtain a uniform surface of the sample, the material was subjected to homogenization and then was pressed to obtain a lozenge measuring a thickness of $10 \mathrm{~mm} \times 5 \mathrm{~mm}$ ). The spectra were measured in the range of $900-1680 \mathrm{~nm}$. The measurements were performed at a temperature of $23^{\circ} \mathrm{C}$ and at a resolution of $3.5 \mathrm{~nm}$. The obtained raw spectra were subjected to SNV (Standard Normal Variate) transformation (using SPECTRAGRYPH software) as the primary technique of pretreatment. For the performance of quantitative analysis, the regression method was used. This method aims to obtain a calibration model that would enable the correlation of information contained in spectra with one or several properties of the sample. For the purposes of the analysis, PLS regression was performed, in which the set of independent variables $X$ consisted of absorbance values for the spectra ranging between 900 and $1680 \mathrm{~nm}$, whereas the set of dependent variables $Y$ consisted of the percentage content of cellulose in samples of buckwheat straw. Validation of the obtained calibration model was performed using Mean Squared Error (MSE) values and Root Mean Squared Error (RMSE) values. The lower the values of both indices, the better the match of the model. XLSTAT version 10 software was used in the analysis of the results. The cellulose to ethanol conversion rate (\%) was calculated according to the formula [8]:

$$
Y=\frac{C_{e} \times V \times 100}{M \times C \times 1.1 \times 0.51} \times 100(\%) ;
$$

where:

$\mathrm{C}_{\mathrm{e}}$ - ethanol concentration $\left(\mathrm{g} / \mathrm{dm}^{3}\right)$

V-sample volume $\left(\mathrm{dm}^{3}\right)$

M-total amount of substrate in the sample (g s.s.)

C-cellulose concentration in the material (\%)

1.1 -cellulose to glucose conversion factor

0.51—glucose to ethanol conversion factor

The content of glucose and ethanol was determined using high performance liquid chromatography. Samples were first centrifuged at $4000 \times \mathrm{g}$ for $10 \mathrm{~min}$ at $4{ }^{\circ} \mathrm{C}$ (The Thermo Scientific Heraeus $(M u l t i f u g e ® 3 S R$ Plus Centrifuge, Darmstadt, Germany) and then were filtered through a $0.22 \mu \mathrm{m}$ membrane filter (Millex-GS, Millipore, USA) prior to analysis using an HPLC system (Merck Hitachi, Pliening, Germany). Glucose and ethanol were separated on an Aminex HPX-87P (Bio-Rad Laboratories $\mathrm{GmbH}$, Munich, Germany) at $30^{\circ} \mathrm{C}$ using a $5 \mathrm{mM} \mathrm{H}_{2} \mathrm{SO}_{4}$ as the mobile phase at a flow rate of $0.6 \mathrm{~cm}^{3} / \mathrm{min}$ and then detected with a refractive index detector (Model L- 7490, Merck Hitachi, Germany). 


\section{Results and Discussion}

\subsection{Influence of Ionic Liquids on the Structure of Buckwheat Straw}

The greatest impediment associated with the production of bioethanol from lignocellulose is the structure of the biomass, which constitutes a complex of three major components-cellulose, hemicellulose, and lignin - of which the first two components should constitute a good source of sugars that can be fermented. The objective of pretreatment with ionic liquids is to disrupt the bonds between the cellulose, hemicellulose, and lignin fibers, and to increase the content of so-called free cellulose, which can be hydrolyzed with the help of enzymes. Certain ionic liquids may cause the removal of lignin, which often constitutes a barrier for enzymes and yeast in the production of ethanol [9]. Therefore, in this study, we examined the applicability of four ionic liquids to process buckwheat straw and demonstrated the effect of ionic liquids on the transformation of the content of cellulose, hemicellulose, and lignin. Furthermore, it was assumed that the task of ionic liquids is to change the structure of cellulose fibers from crystalline to amorphous, increasing the space between the fibers and removal of lignin - the inhibitor of the subsequent hydrolysis and fermentation processes. To this end, 4 different ionic liquids were used for buckwheat pretreatment and the hemicellulose and lignin content was determined in samples before and after treatment. Furthermore, a variant was verified where buckwheat straw was subject to treatment with 2 ILs. The objective of this treatment was removal of lignin with the use of EMIMCl and change of the cellulose structure and disruption of the bonds between fibers via EMIMOAc.

The study of morphology of buckwheat straw under an SEM microscope showed that untreated buckwheat straw had a highly crystalline structure and ordered morphology with minor areas of mechanical damage resulting from the cutting process (Figure 1). However, after the pretreatment with ionic liquids, EMIMOAc and BMIMOAc and after the pretreatment with two ionic liquids (EMIMOAc and EMIMCl), the structure of the cellular walls became loose; cracks between the neighboring cellular walls occurred, and the entire structure of straw particles became scattered and distorted. The photographs below present singular fibers of cellulose, which, following the application of precipitation with deionized water, constituted a bright, adhesive mass surrounded by lignin and hemicellulose. The observed morphological changes were not found for samples treated with EMIMDEP and EMIMCl, which may indicate the lower capacity of these ionic liquids to change the crystallization of cellulose in buckwheat straw.
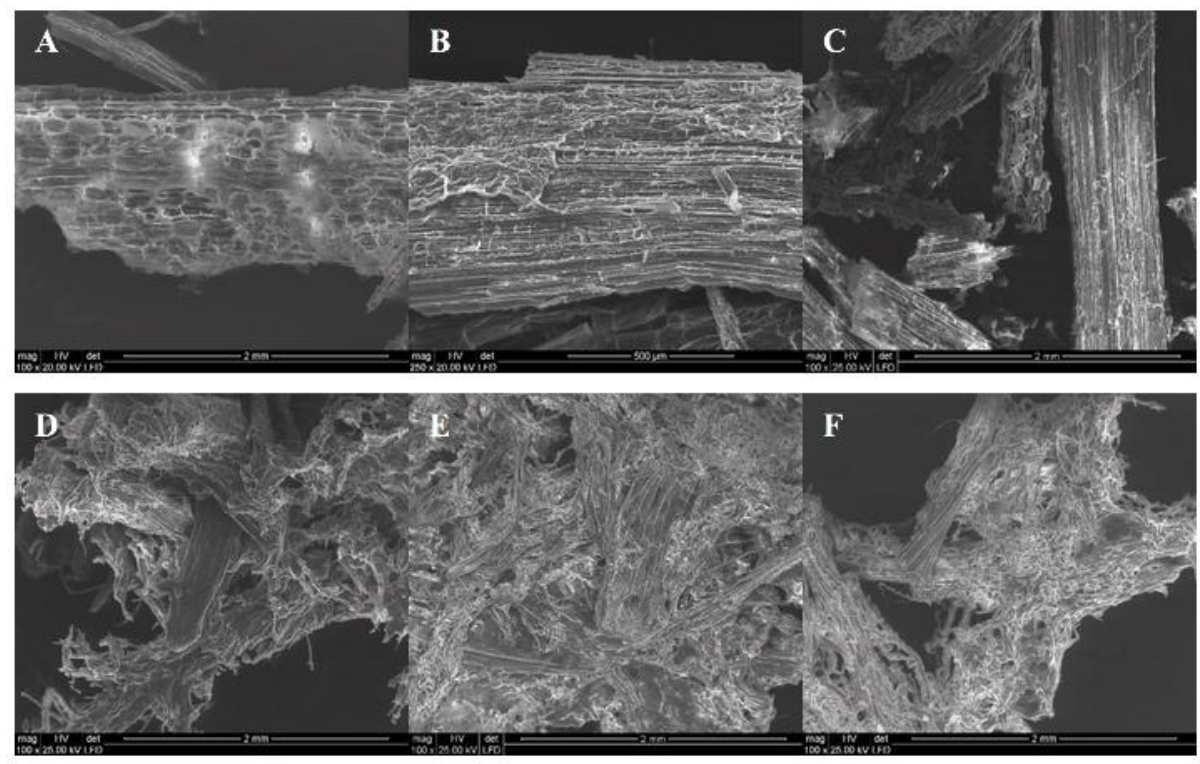

Figure 1. Scanning electron microscopic images of buckwheat straw: (a) without pretreatment; (b) after processing with EMIMCl; (c) after processing with EMIMDEP; (d) after processing with EMIMOAc; (e) after processing with BMIMOAc; and (f) after processing with EMIMOAc and EMIMCl. 
Processing the buckwheat straw with two ionic liquids resulted in the disintegration of the ordered fibrous structure of the biomass as well as reduction in the content of free lignin, which was visible in each sample after purification in the form of soot (stains) on cellulose and hemicellulose fibers. This indicates that, during processing with ionic liquids, lignin is not entirely dissolved and extracted by the solvent; rather, it is only removed from the plant cell walls and transferred outside of the structure. In order to confirm this hypothesis, the content of cellulose, hemicellulose, and lignin was tested in straw samples both before and after processing with ionic liquids (Table 1).

Table 1. Composition of buckwheat straw: untreated and after pretreatment ionic liquids.

\begin{tabular}{cccc}
\hline Type of Pretreatment & Cellulose [\%] & Hemicellulose [\%] & Lignin [\%] \\
\hline Untreated & $42.08 \pm 0.12$ & $8.38 \pm 0.02$ & $16.97 \pm 0.13$ \\
EMIMCl & $29.05 \pm 0.21$ & $18.47 \pm 0.11$ & $11.98 \pm 0.23$ \\
EMIMDEP & $41.49 \pm 0.10$ & $22.27 \pm 0.03$ & $15.26 \pm 0.19$ \\
EMIMOAc & $39.48 \pm 0.07$ & $8.81 \pm 0.07$ & $20.66 \pm 0.08$ \\
BMIMOAc & $36.91 \pm 0.17$ & $9.33 \pm 0.14$ & $14.32 \pm 0.11$ \\
EMIMOAc + EMIMCl & $33.27 \pm 0.08$ & $18.56 \pm 0.22$ & $8.71 \pm 0.12$ \\
\hline
\end{tabular}

The use of EMIMCl to purify buckwheat straw resulted in a decrease in the content of lignin, by approximately $5 \%$. Unfortunately, EMIMCl caused a considerable loss of free cellulose (up to $10 \%$ ) compared with the sample of the native form. Minor changes in the content of lignin were also observed in those samples that were purified with EMIMDEP, but the lignin content was found to be $1.7 \%$ lower, whereas the amount of cellulose remained unchanged. Lower amounts of lignin and cellulose were also demonstrated after purification with BMIMOAc. After processing with EMIMOAc and EMIMCl, a 50\% reduction in the content of lignin was observed, yet the loss of cellulose, which was approximately $9 \%$, was not significant in this case. SEM microscopic analysis showed that only EMIMCl caused delignification of buckwheat straw. Li et al. [10] also indicated delignification of eucalyptus after treatment with BMIMOAc and EMIMOAc. Lignin solubilization during pretreatment with ionic liquids has been reported to be assisted by the $\pi-\pi$ interactions of the ionic liquids' cations with lignin [11]. Purification of buckwheat straw with selected ionic liquids resulted in an increase in the content of hemicellulose in samples. The highest amount of hemicellulose was observed in straw purified with EMIMDEP. Ionic liquids resulted in the release of hemicellulose from the biomass complex, thus facilitating its determination after processing. A higher content of hemicellulose after processing may also be associated with the removal of lignin from the biomass [10]. In unprocessed straw, only $8.38 \%$ of hemicellulose was found, and application of processing with two ionic liquids resulted in an increase in the content of hemicellulose of over 10\%. Literature data indicate higher delignification of lignocellulose when dissolved with acetate-based ionic liquids than that in the case of chloride-based ionic liquids. Moreover, removal of lignin depended on the duration of dissolution of the material in ionic liquids and the temperature of the process [12,13].

The influence of individual ionic liquids on the structure of biomass can also be observed during the spectral analysis of samples in the NIR region. Using an NIR spectrophotometer, and then classification of samples with the PCA method, clear data concerning the applicability of individual ionic liquids for the process of lignocellulose are obtained. The observation chart presents the location of grouping variables in a new dimensional space defined by the F1 and F2 components as determined during the analysis. Buckwheat straw samples were classified in terms of similar Euclidean distances and thus 5 groups were distinguished (Figure 2).

The fifth group consists of buckwheat straw samples after treatment with EMIMOAc and these are most distant from the samples of the first group—buckwheat straw in native form. With the help of the NIR test and PCA classification, it is possible to classify lignocellulosic samples in terms of the amount of cellulose available to enzymes and thus estimate which of these materials will be the best for bioethanol production. In addition, NIR spectra in the range of $900-1680 \mathrm{~nm}$, despite their 
monotonous character, may also provide information on the changes in the structure of the examined straw. The upper peaks of absorption for samples of buckwheat straw are presented in Figure 3.

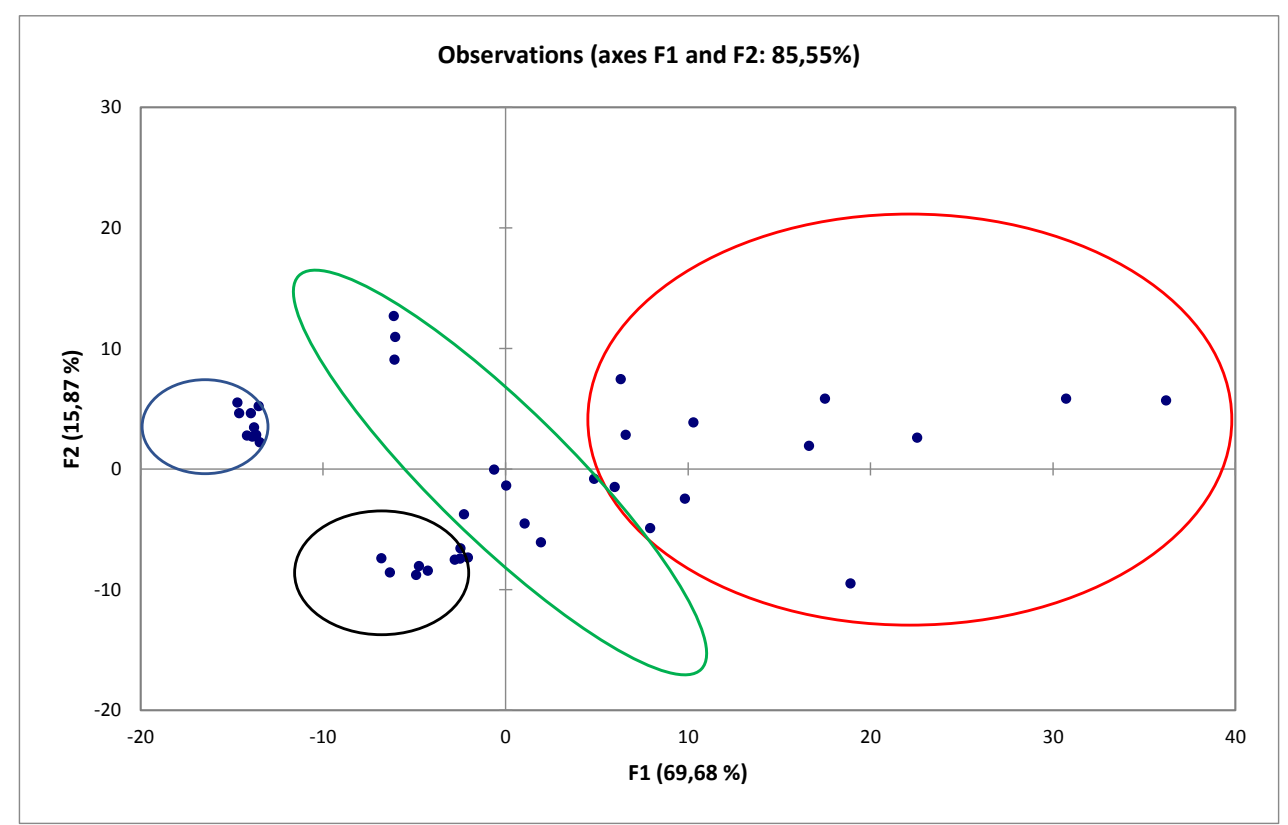

Figure 2. Observation chart: Projection of lignocellulosic biomass onto the space defined by F1 and F2 primary components. 1 (red line)—unprocessed buckwheat straw samples; 2 (green line)—biomass after EMIMCl processing; 3 (black line)—biomass after EMIMOAc and EMIM Cl processing; 4 (bright green line)—buckwheat straw after processing with EMIMDEP, and 5 (blue line)—buckwheat straw after EMIMOAc processing.

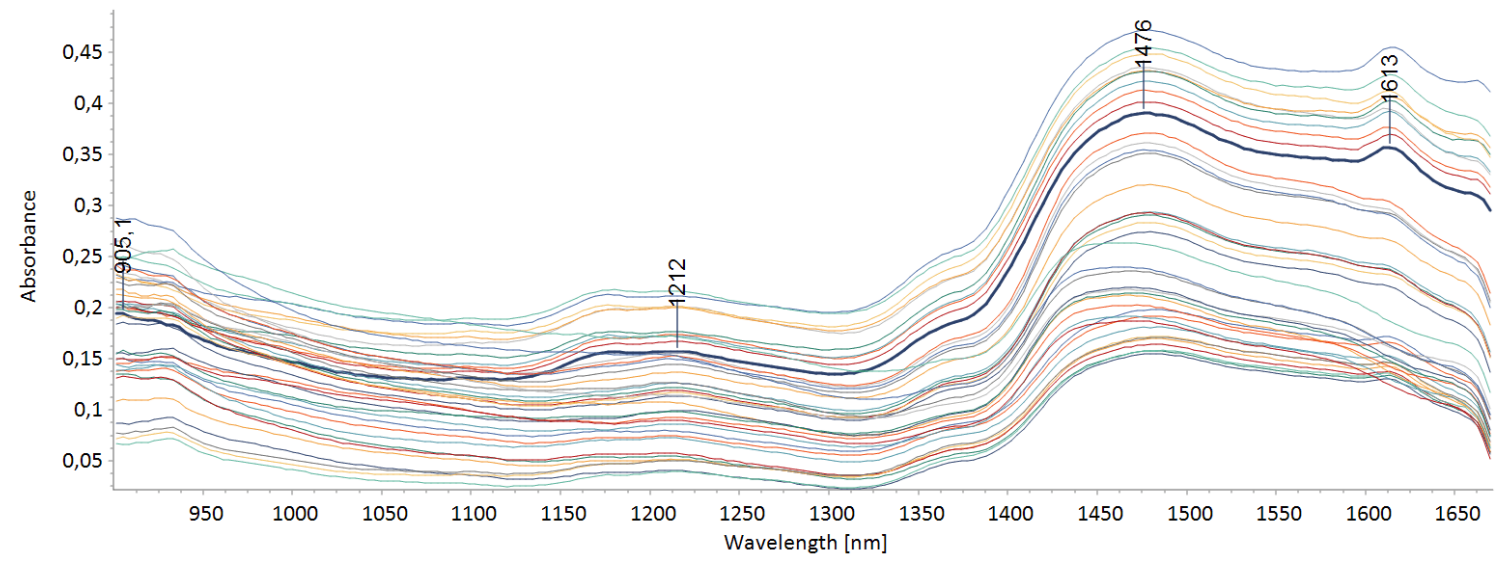

Figure 3. Absorption spectra of buckwheat straw samples in the near-infrared range (900-1680 nm) measured using the reflection technique.

The wide absorption spectrum with a maximum at approximately $1212 \mathrm{~nm}$ results from the presence of valence vibrations $\mathrm{C}-\mathrm{H}$ (a band with lower energy). For the above bond, the basic measurement band is located within the 1600-1650 nm wavelength, with an absorption maximum at $1613 \mathrm{~nm}$. Absorption at $1476 \mathrm{~nm}$ is associated with the presence of a band characteristic of valence vibrations of the O-H group (first band of overtone). The band for this bond with lower energy is also found at a wavelength of $905 \mathrm{~nm}[14,15]$. In order to examine the possibility of the determination of the percentage of cellulose in buckwheat straw based on the measured spectra, the PLS regression analysis was conducted. To achieve this, spectra measured in the entire range were used (900-1680 nm). Table 2 presents the results of this regression analysis. 
Table 2. Example results of determinations of cellulose content in buckwheat straw samples based on the obtained PLS calibration model.

\begin{tabular}{ccccccc}
\hline Model & Range (nm) & Number of Spectra & Number of Variables & $\mathbf{R}^{\mathbf{2}}$ & MSE & RMSE \\
\hline PLS & $900-1680$ & 50 & 1 & 0.9593 & 1.1311 & 1.0635 \\
\hline
\end{tabular}

Analysis of the model showed that the model was correctly matched $\left(R^{2}=0.96\right)$. Low MSE and RMSE values obtained in the analysis also indicate good prediction capability. The developed calibration model was used to predict the percentage content of cellulose, both in raw buckwheat straw as well as after processing with ionic liquids. Table 3 shows example results from the estimation. The obtained results indicate the good accuracy of the model.

Table 3. Example results of determinations of cellulose content in buckwheat straw samples based on the obtained PLS calibration model.

\begin{tabular}{ccc}
\hline \multirow{2}{*}{ Cellulose Content [\%] } & \multicolumn{2}{c}{ PLS } \\
\cline { 2 - 3 } & Predicted Cellulose Content [\%] & Deviation [\%] \\
\hline 29.05 & 29.63 & 2.04 \\
41.49 & 42.83 & 1.65 \\
39.48 & 38.00 & 1.52 \\
42.08 & 41.64 & 2.08 \\
\hline
\end{tabular}

The present method may be of use for the determination of cellulose content in biomass. Such determination is quick and easy, thus being competitive with physicochemical methods utilizing acids and bases. Information on the amount of available cellulose before enzymatic hydrolysis is significant due to the precise selection of the dose of cellulolytic enzymes and it enables minimization of hydrolysis process costs. Furthermore, the NIR data enabled ordering of the type of pretreatment and indicate those where the efficacy is highest. Subsequent research should include further validation of the model, which will enable PLS models to be obtained that are more stable and resistant to fluctuation. Thus, the present study is treated by the authors as a preliminary study, and will naturally be continued.

\subsection{Influence of the Use of Ionic Liquids on Enzymatic Hydrolysis and Alcoholic Fermentation}

The efficacy of enzymatic hydrolysis of lignocellulosic raw materials is strictly linked to the efficacy of biomass pretreatment, which in turn translates into the availability of cellulose [16]. In the first place, the concentration of glucose was determined before and after processing with ionic liquids. The subsequent stage consisted in enzymatic hydrolysis, in which three commercially available enzymatic agents were used. Cellulases from Aspergillus sp. and Trichoderma reesei are enzymes that hydrolyze cellulose, a linear polymer of anhydroglucose units linked together by $\beta-1,4$-glycosidic bonds, to glucose. Endo- $\beta$-D-glucanase is one of the major component enzymes of the cellulase complex. It catalyzes the hydrolysis of cellulose by randomly splitting the sugar residues within the molecule. Exo- $\beta$-D-glucanase and $\beta$-glucosidase can synergistically convert cellulose into glucose and hence are used on an industrial scale [17]. Cellic CTec2 enzymatic preparation is characterized by increased activity of $\beta$-glucosidase, enabling improvement of the efficacy of hydrolysis of lignocellulosic raw materials as a result of restriction of the inhibitory effect of cellobiose.

In accordance with our expectations, glucose was found to be increased in buckwheat straw samples treated with ionic liquids. The highest content of glucose was found in straw purified with EMIMOAc $\left(5.5 \mathrm{~g} / \mathrm{dm}^{3}\right)$ and BMIMOAc $\left(5.1 \mathrm{~g} / \mathrm{dm}^{3}\right)$. The difficulty of enzymatic hydrolysis in untreated lignocellulosic materials was attributed to the presence of hemicelluloses and lignin and their spatial bonds, which created physical barriers that protect cellulose against degradation [18,19]. Lee et al. [20] have demonstrated that the degree of crystallization of cellulose treated with BMIMOAc ionic liquid is lower than that of $\mathrm{BMIMCl}$, which is directly linked to the lower conversion degree of lignocellulose purified with chloride-based ionic liquids. 
Our results demonstrated a lack of association between delignification of buckwheat straw with EMIMCl or EMIMDEP ionic liquids with more efficient enzymatic hydrolysis. However, glucose content was found to increase after the hydrolysis of samples purified with EMIMOAc and BMIMOAc. Thus, this confirms that the complete removal of lignin and hemicellulose is not necessary. However, the use of acetate-based ionic liquids (EMIMOAc and BMIMOAc) is more important, as they efficiently facilitate the access of enzymes to cellulose with a lower degree of crystallization, which is a good source of fermenting sugars [19]. With regards to the above, the amount of glucose found in buckwheat straw purified with EMIMOAc and BMIMOAc and after enzymatic hydrolysis was no higher than that of purification with EMIMOAc alone.

Thus, future studies with respect to the use of ionic liquids with lignocellulosic raw materials should place special emphasis on the search for solvents that will mainly result in the depolymerization of cellulose, and that will not, as demonstrated by the currently available literature, lead to the delignification of the material $[9,21,22]$. Removal of lignin in the process of bioethanol production from biomass may be significant primarily from the economic standpoint, as lignin itself is a valuable waste that is utilized in numerous industrial applications such as the energy, textile, paper, and other industries [23,24].

Another significant stage in second generation bioethanol production is the selection of a suitable enzymatic agent, which will enable the "release" of the fermenting sugars, which will be used in the process of fermentation in the next stage. It is important that the application of the selected enzymatic preparation is favorable from the economic standpoint (the price), and the applied dose is correctly chosen.

In this study, we tested the use three enzymatic agents that will enable a concomitant efficient hydrolysis of cellulose as well as ethanol fermentation without being disrupted by the presence of inhibitors. According to the results, the highest level of efficiency in hydrolysis was obtained by using the Cellic CTec2 agent, irrespective of the type of ionic liquid used. The highest content of glucose after treatment with Cellic CTec2 was $5.5 \mathrm{~g} / \mathrm{dm}^{3}$ followed by the use of EMIMOAc and $5.1 \mathrm{~g} / \mathrm{dm}^{3}$ followed by the use of BMIMOAc. The lowest amount of glucose was recorded for samples where cellulase from Aspergillus sp. was used, irrespective of the type of ionic liquid used earlier (Figure 4).

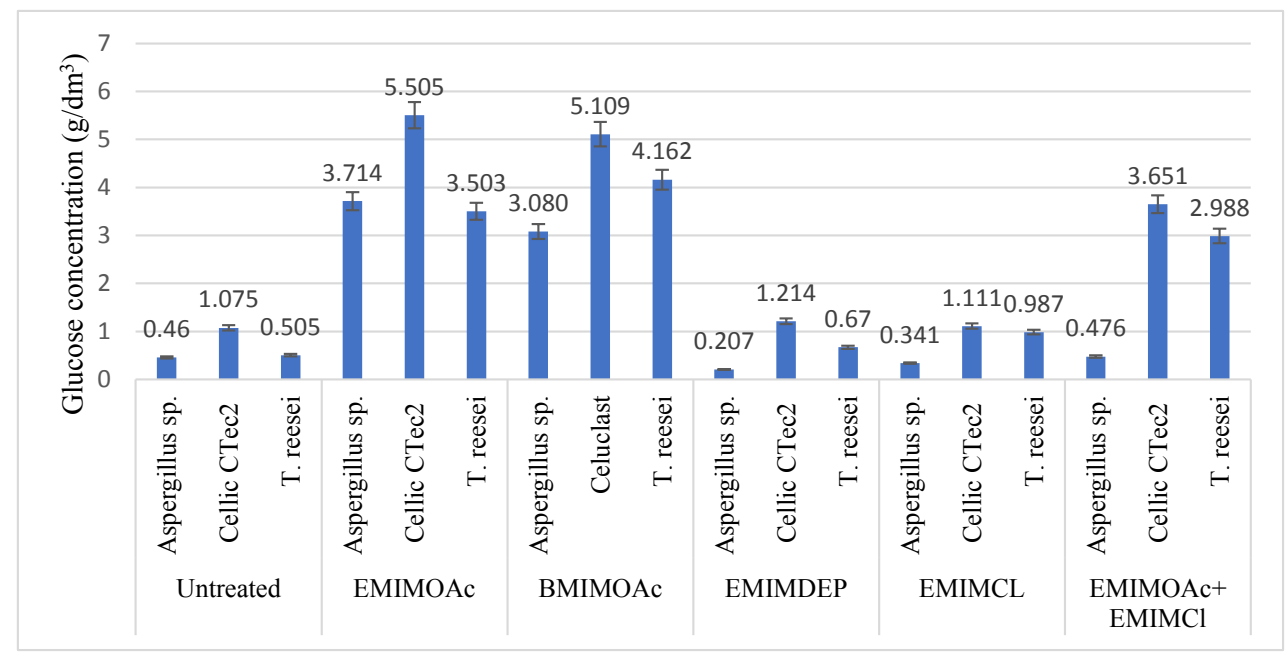

Figure 4. Glucose content after 96 h enzymatic hydrolysis of untreated buckwheat straw samples and samples treated with ionic liquids.

In the next stage, we studied the ethanol fermentation process on the prepared raw material (Figure 5). The fermentation process was performed using S. cerevisiae yeast. According to the results, the highest ethanol concentration was obtained for those variants where the following ionic liquids were used: EMIMOAc and Cellic CTec2 $\left(2.46 \mathrm{~g} / \mathrm{dm}^{3}\right)$ and in the variant with BMIMOAc and T. reesei $\left(3.31 \mathrm{~g} / \mathrm{dm}^{3}\right)$. These results are compatible with the amount of sugar, and the concentration of glucose, 
which at the beginning of the fermentation process was $5.5 \mathrm{~g} / \mathrm{dm}^{3}$ and $4.16 \mathrm{~g} / \mathrm{dm}^{3}$, respectively. The lowest concentration of fermenting sugars was obtained after enzymatic hydrolysis using cellulase from Aspergillus sp., which translated into the lowest ethanol concentrations. The environment to which microorganisms are introduced (after pretreatment with ionic liquids and after enzymatic hydrolysis) is typically not favorable for the microorganisms performing the process of ethanol fermentation [25-27]. The presence of an ionic liquid in the fermentation environment, as well as inhibitors constituting the outcome of enzymatic hydrolysis, the source of which is the raw material itself, may have a negative impact on the microorganisms involved in the fermentation process. Indisputably, microorganisms are the weakest link in the process of obtaining ethanol from lignocellulosic raw materials. Thus, not only is the control of yeast count important but also their viability as the specific marker (indicator) of the proper course of the bioprocess is important. In our experiments, the highest count of yeast $\left(8.4 \times 10^{5}\right.$ $\mathrm{CFU})$ in combination with a high yeast viability $(78 \%)$ was demonstrated for the variant EMIM OAC + Cellic CTec2, which translated into a high concentration of ethanol. In addition, high counts $\left(4.5 \times 10^{5}\right.$ $\mathrm{CFU})$ and viability $(81 \%)$ were determined for the variant EMIMOAc + EMIMCl in combination with the enzymatic agent from T. reesei (Table 4). While in the first case, the glucose concentration as well as the counts and viability of yeast translated into a high ethanol concentration, in the second variant, the concentration of ethanol was lower $\left(1.22 \mathrm{~g} / \mathrm{dm}^{3}\right)$ due to the smaller pool of available fermenting sugars $\left(2.98 \mathrm{~g} / \mathrm{dm}^{3}\right)$. A chromatographic analysis demonstrated that the substrate concentration at $96 \mathrm{~h}$ of fermentation in all analyzed variants was zero (results not shown), thus indicating that the entire pool of fermenting sugars was used. The complete use of glucose by the $S$. cerevisiae strain shows that the process had a correct course. However, only analysis of the detailed kinetics of glucose as well as analysis of kinetic indicators such as the productivity of the bioprocess would allow a detailed interpretation of the influence of individual variables on the process of ethanol fermentation. Moreover, an increase in the substrate concentration subjected to the technological process seems to be a key factor. On the one hand, an increase in the pool of fermenting sugars would translate into greater production of ethanol; yet on the other hand, the efficiency of pretreatment and enzymatic hydrolysis, and their influence on microorganisms leading to the fermentation, in this case higher inhibitor concentration, are questionable. Overall, this could have influenced the efficacy of fermentation. In addition, yeast viability was found to be in the range of $43-81 \%$, which may indicate the negative impact of factors in the mixture subject to fermentation. However, in this case, the factor influencing reduced yeast viability may be due to the low concentration of glucose.

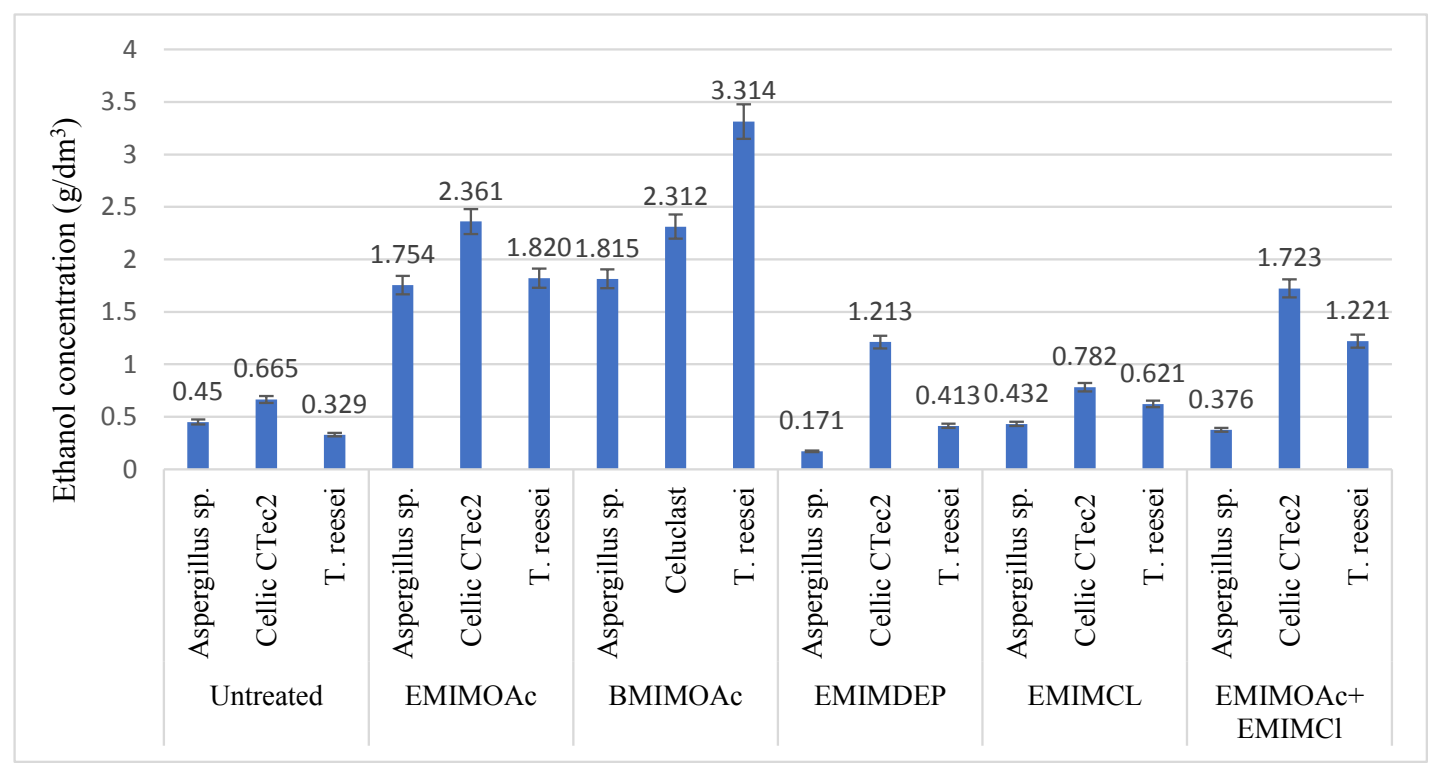

Figure 5. Ethanol content after $96 \mathrm{~h}$ alcoholic fermentation of untreated buckwheat straw samples and samples treated with ionic liquids. 
Table 4. Counts and viability of yeast cells after alcoholic fermentation of buckwheat straw samples before and after treatment with ionic liquids and conversion of cellulose to ethanol for individual samples.

\begin{tabular}{ccccc}
\hline Sample & Enzyme Type & Cell Viability (\%) & Cell Count (CFU) & $\begin{array}{c}\text { Cellulose to Ethanol } \\
\text { Conversion (\%) }\end{array}$ \\
\hline \multirow{3}{*}{ Untreated } & Aspergillus sp. & $55 \% \pm 1.1 \%$ & $4.0 \times 10^{6}$ & $15.25 \%$ \\
& Cellic CTec2 & $61 \% \pm 0.9 \%$ & $3.1 \times 10^{5}$ & $22.54 \%$ \\
& T. reesei & $60 \% \pm 1.9 \%$ & $2.9 \times 10^{5}$ & $11.15 \%$ \\
\hline \multirow{2}{*}{ EMIMOAc } & Aspergillus sp. & $69 \% \pm 0.7 \%$ & $9.0 \times 10^{6}$ & $63.23 \%$ \\
& Cellic CTec2 & $78 \% \pm 0.9 \%$ & $8.4 \times 10^{5}$ & $83.10 \%$ \\
& T. reesei & $75 \% \pm 2.1 \%$ & $7.6 \times 10^{5}$ & $65.76 \%$ \\
\hline \multirow{2}{*}{ BMIMOAc } & Aspergillus sp. & $67 \% \pm 2.2 \%$ & $6.0 \times 10^{6}$ & $70.14 \%$ \\
& Cellic CTec2 & $72 \% \pm 1.9 \%$ & $8.0 \times 10^{5}$ & $89.35 \%$ \\
& T. reesei & $70 \% \pm 1.8 \%$ & $5.5 \times 10^{5}$ & $128.07 \%$ \\
\hline \multirow{2}{*}{ EMIMDEP } & Aspergillus sp. & $54 \% \pm 1.4 \%$ & $3.0 \times 10^{6}$ & $5.88 \%$ \\
& Cellic CTec2 & $57 \% \pm 2.1 \%$ & $3.4 \times 10^{5}$ & $41.71 \%$ \\
& T. reesei & $56 \% \pm 1.4 \%$ & $2.6 \times 10^{5}$ & $14.20 \%$ \\
\hline \multirow{2}{*}{ EMIMCl } & Aspergillus sp. & $51 \% \pm 0.7 \%$ & $3.2 \times 10^{6}$ & $21.22 \%$ \\
& Cellic CTec2 & $55 \% \pm 0.6 \%$ & $4.5 \times 10^{5}$ & $38.42 \%$ \\
\hline \multirow{2}{*}{ EMIMOAc+ } & T. reesei & $43 \% \pm 1.5 \%$ & $4.0 \times 10^{5}$ & $30.51 \%$ \\
EMIMC1 & Aspergillus sp. & $74 \% \pm 0.5 \%$ & $5.0 \times 10^{6}$ & $16.22 \%$ \\
& Cellic CTec2 & $78 \% \pm 2.1 \%$ & $6.6 \times 10^{5}$ & $73.86 \%$ \\
\hline
\end{tabular}

One of the main issues in the production of bioethanol from lignocellulose is the low concentration of ethanol obtained as the effect of the fermentation process. This was also observed in this study. The final concentration of ethanol is influenced by the concentration of the substrate and the efficiency of enzymatic hydrolysis, which is associated with the availability of cellulose (efficiency of pretreatment) and its content in the raw materials. Selection of the correct raw material, type of pretreatment, and selection of enzymatic agent as well as its doses are the key diagnostic issues to be met during the development of a method utilizing a new raw material [28-31]. Moreover, present-day biotechnology does not only have to deal with the development of screening of microorganisms with industrial potential, which will enable the development of markers used in the selection of proper microorganisms for the process of fermentation. The challenge is also to choose microorganisms that can use hexoses and pentoses and that are resistant to toxins and inhibitors, which are present due to the degradation of lignin [32,33]. Such compounds formed during fermentation often block ethanol fermentation (e.g., furfural, methylhydroxyfurfural, acetic acid, lactic acid, phenols, aldehydes, and heavy metal ions). Due to the absence of such natural microorganisms, the use of metabolic engineering to construct organisms with the required characters has been gaining interest. This enhances the activity of cells as a result of enhanced enzymatic, transportation, and regulatory functions by means of DNA recombination. Such interest includes analysis of metabolic pathways, design of genetic changes, and creation of recombined cells with changed properties [34].

\section{Conclusions}

In this study, we have demonstrated the possibility of obtaining bioethanol from buckwheat straw using ionic liquid for the pretreatment of the raw material prior to its enzymatic hydrolysis and alcoholic fermentation.

In the present study, the best results were obtained using 1-ethyl-3-methylimidazolium acetate and Cellic CTec2 enzymatic preparations for pretreatment of buckwheat straw. The glucose content after $72 \mathrm{~h}$ of enzymatic hydrolysis was $5.5 \mathrm{~g} / \mathrm{dm}^{3}$ (with the use of EMIMOAc), whereas the highest concentration of bioethanol $\left(3.31 \mathrm{~g} / \mathrm{dm}^{3}\right)$ was obtained by using BMIMOAc for the pretreatment of 
straw and T. reesei cellulase for enzymatic hydrolysis. The efficiency of the fermentation process is strictly linked to the pool available to fermenting sugars.

This research has demonstrated that EMIMOAc and BMIMOAC ionic liquids are more efficient in dissolving cellulose and produce more pronounced changes in the cellulose fiber structure than EMIMCl and EMIMDEP. However, pretreatment with EMIMCl resulted in greater delignification of the material than occurred with the remaining ionic liquids. For the pretreatment of buckwheat straw, treatment with EMIMOAC and EMIMCl was used in order to produce the delignification effect and the concomitant increase in amorphous sites in the biomass structure. This method resulted in reduced lignin content in the sample after pretreatment (to approx. $8 \%$ ), but it did not lead to an increase in the hydrolysis efficiency.

The PLS model enabled the determination of the percentage content of cellulose in buckwheat straw, which might constitute a quick and interesting alternative to analytical methods used currently. The NIR spectra of the raw material provided information on changes occurring within its structure. Information in the form of NIR spectra with chemometric data analysis can be used as a tool for the rapid determination of the amount of cellulose in raw material; this knowledge can be extended to alter the physicochemical processes of the raw material. This is important because it enables better selection of the number of enzymes, depending on the amount of available cellulose after pretreatment. If future bioethanol production from biomass includes pretreatment followed by enzymatic hydrolysis, the prompt use of NIR tests will reduce the costs associated with precise selection of the dose of enzymes to the amount of cellulose in the material, which remains after treatment. The described method will constitute the subject of future research to be conducted by the authors.

Author Contributions: The following statements should be used: conceptualization, M.S.K., D.S.P., L.B., B.W., R.M., J.K.C., K.G. and J.C.P.; methodology, M.S.K., D.S. and B.W. and J.C.P.; software, J.K.C, M.S.K and J.C.P.; validation, J.K.C, M.S.K. and B.W.; formal analysis, M.S.K., B.W. and J.C.P.; investigation, M.S.K.; resources, M.S.K., D.S. and J.K.C.; data curation, M.S.K, J.K.C. and J.C.P.; writing-original draft preparation, M.S.K., D.S.P., L.B., B.W., R.M., J.K.C., K.G. and J.C.P; writing-review and editing, M.S.K., D.S.P., L.B., B.W., R.M., J.K.C., K.G. and J.C.P.; visualization, B.W.; supervision, M.S.K and D.S.; project administration, M.S.K.; funding acquisition, M.S.K.

Funding: This research was funded by the NATIONAL SCIENCE CENTER (POLAND), grant number DEC-2017/01/X/NZ9/00357.

Conflicts of Interest: The authors declare no conflict of interest.

\section{References}

1. Zarzecka, K.; Gugała, M.; Mystkowska, I. Nutritional value and opportunities of using buckwheat. Postępy Fito 2014, 1, 28.

2. Alvira, P.; Tomas-Pejo, E.; Ballesteros, M.; Negro, M.J. Pretreatment technologies for an efficient bioethanol production process based on enzymatic hydrolysis: A Review. Bioresour. Technol. 2010, 101, 4851. [CrossRef]

3. Holm, J.; Lassi, U. Ionic liquids in pretreatment of lignocellulosic biomass In Ionic Liquids: Application and Perspectives; Kokorin, A., Ed.; IntechOpen: Rijeka, Croatia, 2011; pp. 546-560.

4. Pinkert, A.; Marsh, K.N.; Pang, S.; Staiger, M.P. Ionic liquids and their interaction with cellulose. Chem. Rev. 2009, 109, 6712. [CrossRef] [PubMed]

5. Zhu, S. Use of ionic liquids for the efficient utilization of lignocellulosic materials. J. Chem. Technol. Biotechnol. 2008, 83, 777. [CrossRef]

6. Samayam, I.P.; Hanson, L.B.; Langan, P.; Schall, C.A. Ionic-liquid induced changes in cellulose structure associated with enhanced biomass hydrolysis. Biomacromolecules 2011, 12, 3091. [CrossRef]

7. Brandt, A.; Hallett, J.P.; Leak, D.J.; Murphy, R.J.; Welton, T. The effect of the ionic liquid anion in the pretreatment of pine wood chips. Green Chem. 2010, 12, 672-679. [CrossRef]

8. Liu, K.; Lin, X.; Yue, J.; Li, X.; Fang, X.; Zhu, M.; Lin, J.; Qua, J.; Xiao, L. High concentration ethanol production from corncob residues by fed-batch strategy. Bioresour. Technol. 2010, 101, 4952-4958. [CrossRef]

9. Smuga-Kogut, M.; Zgórska, K.; Szymanowska-Powałowska, D. Influence of the crystalline structure of cellulose on the production of ethanol from lignocellulose biomass. Int. Agrophys. 2016, 30, 83-88. [CrossRef] 
10. Li, H.Y.; Chen, X.; Wang, C.Z.; Sun, S.N.; Sun, R.C. Evaluation of the two-step treatment with ionic liquids and alkali for enhancing enzymatic hydrolysis of Eucalyptus: Chemical and anatomical changes. Biotechnol. Biofuels 2016, 9, 166. [CrossRef] [PubMed]

11. Shill, K.; Padmanabhan, S.; Xin, Q.; Prausnitz, J.M.; Clark, D.S.; Blanch, H.W. Ionic liquid pretreatment of cellulosic biomass: Enzymatic hydrolysis and ionic liquid recycle. Biotechnol. Bioeng. 2011, 108, 511. [CrossRef]

12. Qiu, Z.; Aita, G.M.; Walker, M.S. Effect of ionic liquid pretreatment on the chemical composition, structure and enzymatic hydrolysis of energy cane bagasse. Bioresour. Technol. 2012, 117, 251-256. [CrossRef] [PubMed]

13. Doherty, T.V.; Mora-Pale, M.; Foley, S.E.; Linhardt, R.J.; Dordick, J.S. Ionic liquid solvent properties as predictors of lignocellulose pretreatment efficacy. Green Chem. 2010, 12, 1967-1975. [CrossRef]

14. Tuchołka, D. Methods of Absorption and Reflection Spectroscopy in Chemical Analysis. Ph.D. Thesis, University of Agriculture in Poznan, Poznan, Poland, 1996.

15. Kocjan, R. Analytical Chemistry T. 2 Instrumental Analysis; Medical Publishing PZWL: Warsaw, Poland, 2014; pp. 231-247.

16. Ji, Z.; Zhang, X.; Ling, Z.; Zhou, X.; Ramaswamy, S.; Xu, F. Visualization of Miscanthus giganteus cell wall deconstruction subjected to dilute acid pretreatment for enhanced enzymatic digestibility. Biotechnol. Biofuels 2015, 8, 1. [CrossRef]

17. Horn, S.J.; Vaaje-Kolstad, G.; Westereng, B.; Eijsink, V.G.H. Novel enzymes for the degradation of cellulose. Biotechnol. Biofuels 2012, 5, 45. [CrossRef]

18. Uju, S.Y.; Nakamoto, A.; Goto, M.; Tokuhara, W.; Noritake, Y.; Katahira, S.; Ishida, N.; Nakashima, K.; Ogino, C.; Kamiya, N. Short time ionic liquids pretreatment on lignocellulosic biomass to enhance enzymatic saccharification. Bioresour. Technol. 2012, 103, 446-452. [CrossRef]

19. Sun, S.; Cao, X.; Sun, S.; Xu, F.; Song, X.; Jones, G. Improving the enzymatic hydrolysis of thermo-mechanical fiber from Eucalyptus urophylla by a combination of hydrothermal pretreatment and alkali fractionation. Biotechnol. Biofuels 2014, 7, 116. [CrossRef] [PubMed]

20. Lee, S.H.; Doherty, T.V.; Linhardt, R.J.; Dordick, J.S. Ionic liquid-mediated selective extraction of lignin from wood leading to enhanced enzymatic cellulose hydrolysis. Biotechnol. Bioeng. 2009, 102, 1368-1376. [CrossRef]

21. Boeriu, C.G.; Bravo, D.; Gosselink, R.J.; van Dam, J.E. Characterization of structure-dependent functional properties of lignin with infrared spectroscopy. Ind. Crops Prod. 2004, 20, 205-218. [CrossRef]

22. Hou, X.D.; Li, N.; Zong, M.H. Renewable bio ionic liquids-water mixtures-mediated selective removal of lignin from rice straw: Visualization of changes in composition and cell wall structure. Biotechnol. Bioeng. 2013, 110, 1895-1902. [CrossRef] [PubMed]

23. Sahoo, S.; Seydibeyoglu, M.O.; Mohanty, A.K.; Misra, M. Characterization of industrial lignins for their utilization in future value added applications. Biomass Bioenergy 2011, 35, 4230-4237. [CrossRef]

24. Cotana, F.; Cavalaglio, G.; Nicolini, A.; Gelosia, M.; Coccia, V.; Petrozzi, A.; Brinchi, L. Lignin as co-product of second generation bioethanol production from lignocellulosic. Energy Procedia 2014, 45, 52-60. [CrossRef]

25. Mehmood, N.; Husson, E.; Jacquard, C.; Wewetzer, S.; Büchs, J.; Sarazin, C.I. Impact of two ionic liquids, 1-ethyl-3-methylimidazolium acetate and 1-ethyl-3-methylimidazolium methylphosphonate, on Saccharomyces cerevisiae: Metabolic, physiologic, and morphological investigations. Biotechnol. Biofuels 2015, 8, 17. [CrossRef] [PubMed]

26. Sitepu, I.R.; Shi, S.; Simmons, B.A.; Singer, S.W.; Boundy-Mills, K.; Simmons, C.W. Yeast tolerance to the ionic liquid 1-ethyl-3-methylimidazolium acetate. FEMS Yeast Res. 2014, 14, 1286-1294. [CrossRef] [PubMed]

27. Qing, Q.; Yang, B.; Wyman, C.E. Xylooligomers are strong inhibitors of cellulose hydrolysis by enzymes. Bioresour. Technol. 2010, 101, 9624-9630. [CrossRef]

28. Giri, F.M.; Fonseca, C.; Carvalheiro, F.; Duarte, L.C.; Marques, S.; Bogel-Lukasic, R. Hemicelluloses for fuel ethanol: A review. Bioresour. Technol. 2010, 101, 4775-4800. [CrossRef]

29. Gamage, J.; Howard, L.; Zisheng, Z. Bioethanol production from lignocellulosic biomass. J. Biobased Mater. Bioenerg. 2010, 4, 3-11. [CrossRef]

30. Garver, M.P.; Liu, S. Development of thermochemical and biochemical technologies for biorefineries. In Bioenergy Research: Advances and Applications, 1st ed.; Gupta, V.K., Tuohy, M.G., Kubicek, C.P., Saddler, J., Xu, F., Eds.; Publisher: Elsevier, Netherlands, 2014; Volume 27, pp. 457-488. 
31. Álvarez, C.; Manuel Reyes-Sosa, F.; Díez, B. Enzymatic hydrolysis of biomass from wood. Microbiol. Biotechnol. 2016, 9, 149-156. [CrossRef] [PubMed]

32. Yang, Q.; Pan, X. Correlation between lignin physicochemical properties and inhibition to enzymatic hydrolysis of cellulose. Biotechnol. Bioeng. 2016, 113, 1213-1224. [CrossRef] [PubMed]

33. Lee, Y.G.; Jin, Y.S.; Cha, Y.L.; Seo, J.H. Bioethanol production from cellulosic hydrolysates by engineered industrial Saccharomyces cerevisiae. Bioresour. Technol. 2017, 228, 355-361. [CrossRef] [PubMed]

34. Dickinson, Q.; Bottoms, S.; Hinchman, L.; McIlwain, S.; Li, S.; Myers, C.L.; Boone, C.; Coon, J.J.; Hebert, A.; Sato, T.K.; et al. Mechanism of imidazolium ionic liquids toxicity in Saccharomyces cerevisiae and rational engineering of a tolerant, xylose-fermenting strain. Microbial. Cell Fact. 2016, 15, 17. [CrossRef] [PubMed]

C 2019 by the authors. Licensee MDPI, Basel, Switzerland. This article is an open access article distributed under the terms and conditions of the Creative Commons Attribution (CC BY) license (http://creativecommons.org/licenses/by/4.0/). 